\title{
ENTREVISTA
}

\section{AGCID, tres décadas gestionando la cooperación internacional en el país}

\author{
En entrevista con esta publicación, su Director Ejecutivo, Embajador Juan \\ Pablo Lira, realiza un completo balance de la gestión de la agencia y \\ proyecta sus principales desafíos para los próximos años.
}

E ste 19 de junio, la Agencia Chilena de Cooperación Internacional para el Desarrollo (AGCID) conmemora 30 años desde su creación, al alero del entonces Ministerio de Planificación y Cooperación de Chile (mideplan) y en un contexto de reinserción internacional y de restablecimiento democrático de Chile, por lo que debió ir adaptándose a un escenario de transformación, como bien explica su actual Director Ejecutivo, el embajador Juan Pablo Lira.

En entrevista con revista Estudios Internacionales, el diplomático de carrera se refiere a los objetivos fundacionales de este organismo encargado de gestionar la cooperación internacional en el país.

"Dentro de sus objetivos fundacionales podemos señalar la transferencia de conocimientos, con la finalidad de fortalecer nuestra capacidad tecnológica y científica. Esto se tradujo, por ejemplo, en el otorgamiento de becas y estancias de profesionales chilenos en el extranjero, así como también la organización de seminarios y actividades de formación académica en coordinación con universidades chilenas. Otro objetivo tenía relación con el desarrollo económico y social del país, que en esos momentos estaba atravesando profundos desafíos en un contexto internacional de grandes cambios, por lo que era necesario poder contar con una fuente de recursos financieros y técnicos que nos permitieran transitar por los nuevos escenarios globales", destaca.

En este mismo contexto, añade que existe un elemento interesante en el origen de la AGCID. "En sus inicios, cuando estaba directamente vinculada con MIDEPLAN, articulaba muchas de sus acciones con el Ministerio de Relaciones Exteriores. En virtud de lo anterior, podemos mencionar que otro e importante objetivo fue reforzar y actuar en coordinación con la política exterior del país, con la finalidad de fortalecer la presencia de Chile en el exterior, a través de la proyección internacional de su capacidad científica, tecnológica y comercial, 
así como recibir la solidaridad democrática después de casi diecisiete años de dictadura".

\section{-¿Cuáles fueron las prioridades establecidas por la autoridad de aquel entonces en materia de Cooperación y Desarrollo?}

-Considerando lo mencionado anteriormente, es necesario tener en cuenta el contexto político de inicios de los ' 90 , tanto en Chile como en América Latina. En el caso de Chile, el proceso de recuperación de la democracia atrajo el interés de países desarrollados que quisieron contribuir y acompañar la nueva etapa que comenzaba en el país. El gobierno de la época, tal y como lo venían enfatizando presidentes como Eduardo Frei en los años '60, tenía la convicción que el desarrollo de Chile era un desafío propio y por el cual estábamos llamados a trabajar como país en su conjunto. Sin embargo, también existía conciencia que el desarrollo no se podría lograr de manera aislada, sino que era una tarea compartida. La institucionalización de la cooperación, a través de la creación de la AGCID, permitió gestionar y articular los recursos provenientes de la cooperación internacional y enfocarlos hacia las áreas prioritarias para el desarrollo nacional. Este elemento fue crucial en los primeros años de la Agencia, ya que los recursos ingresaban en la medida que se presentaban proyectos atractivos para los cooperantes, los cuales se lograban a través de acuerdos y negociaciones que permitían sentar unas bases claras y transparentes para la cooperación internacional. En este sentido, uno de los ejes prioritarios que abordó el gobierno de la época, a través de la cooperación para el desarrollo, fue la superación de la pobreza, considerando programas en el área de vivienda, salud y educación, además de apoyo a programas de alcance directo gestionados por el Fondo de Solidaridad e Inversión Social (Fosis).

Otra de las prioridades vinculadas al desarrollo nacional era el apoyo al trabajo científico y tecnológico enfocado, entre otras cosas, en la innovación en los procesos productivos. En este punto, las universidades jugaron un rol muy importante, ya que a través de pasantías, seminarios y programas académicos, se consiguió avanzar de manera sustancial en esta materia.

Para poder apoyar el proceso de desarrollo que se esperaba llevar a cabo, era fundamental contar con infraestructura adecuada, transformándose así en otro de los pilares a potenciar. Aquí la cooperación internacional fue clave y además muy reconocible, como por ejemplo la construcción del Terminal Pesquero de la Región Metropolitana, que comenzó en 1994 gracias a la cooperación japonesa.

Otro de los ejes prioritarios, fue el cuidado del medioambiente y la solución de problemas específicos como, por ejemplo, la contaminación ambiental, además de enfocar los esfuerzos en la protección de nuestros recursos naturales. 
Finalmente, debemos mencionar la importancia de la modernización del Estado, con el fin de potenciar su eficiencia. En este ámbito, ejemplo de ello fue la contribución al proceso de puesta en marcha de los gobiernos regionales y de las administraciones provinciales y locales en 1992, para lo cual fue fundamental el aporte de España, Francia, Inglaterra, Noruega y la Comunidad Europea de ese entonces.

\section{-A propósito del intento de superación del paradigma tradicional de Coope-} ración Norte-Sur, en 1993 se crea el Programa de Cooperación Técnica entre Países en Desarrollo (hoy, Programa de Cooperación Sur-Sur). ¿En qué consiste dicho programa y cuál es el balance que puede hacer de su funcionamiento? -El Plan de Acción de Buenos Aires (PABA 1978), orientado a promover y realizar la cooperación técnica entre los países en desarrollo, constituye el antecedente de algunas decisiones que muy tempranamente asume la cooperación chilena. En el año 1991, a partir de la intervención del Presidente Patricio Aylwin en la Cumbre de Países Centroamericanos en San Salvador, Chile adquiere el compromiso de establecer cooperación técnica y ofrecer becas de formación de capital humano para los países del área del Caribe. Entre ese momento y el año 1993, cuando formalmente se inicia el programa, otras acciones apuntan en el mismo sentido. Así, nuestro país desarrolla iniciativas que se enmarcan dentro del espíritu de lo que posteriormente adquirirá una forma sustantiva en el marco de la Cooperación Técnica para el Desarrollo (CTPD); se trata de misiones y seminarios exploratorios, de los cuales podemos citar, a manera de ejemplo, Colombia, Bolivia y México.

El programa de Cooperación Técnica entre Países en Desarrollo (cooperación horizontal) buscaba prestar asistencia a países de igual o menor desarrollo relativo que Chile. Se estructuraba a partir de dos componentes: asistencia técnica y la formación de recursos humanos. La asistencia técnica trataba de impulsar el desarrollo de consultorías por parte de expertos chilenos; permitía el desarrollo de pasantías de profesionales extranjeros en el país; propiciaba la generación de misiones de expertos de Chile a sectores o instituciones de países beneficiarios; procuraba realizar seminarios nacionales y regionales en países que recibían este beneficio, entre otros. La formación de recursos humanos se expresaba en el otorgamiento de becas a personas de países que tuvieran un nivel de desarrollo relativo similar o inferior al nuestro, lo cual incluía estudios de postgrado, cursos internacionales (en Chile u otros países) en una modalidad de triangulación. El programa se dirigía a la región de América Latina y el Caribe.

La creación de este programa encuentra su motivación en el marco de los objetivos que impulsaron la fundación de AGCID: "proyectar internacionalmente las capacidades cientificas, tecnológicas y de comercio de Chile, con el propósito de 
lograr una efectiva presencia internacional del país y promover los procesos de integración y cooperación horizontales entre países en desarrollo". ${ }^{1} \mathrm{El}$ balance a tantos años de distancia solo puede ser positivo, más allá de las carencias que pudiéramos detectar. Entendemos la cooperación Sur-Sur como el resultado de experiencias compartidas y de afinidades, cimentada en objetivos y solidaridad comunes, guiados por los principios de respeto, soberanía e implicancias nacionales, libre de cualquier condicionalidad. Entendemos la cooperación Sur-Sur como técnica y no financiera, la cual se expresa mediante acciones directas y proyectos, todo lo cual supone un esfuerzo principal en lo relativo a traspaso de capacidades y conocimientos, básicamente en materia de políticas públicas y en formación de recursos humanos.

Nuestra forma de plantear la cooperación Sur-Sur supone un plano de horizontalidad y no condicionamiento, convicciones fuertemente internalizadas en nuestra acción y de las cuales da cuenta nuestra labor en la Región de América Latina y el Caribe. Procuramos trabajar con cada país asociado las prioridades y oportunidades de los temas de cooperación, para lo cual consideramos nuestras propias fuerzas, conocimientos y capacidades. De manera similar buscamos una ejecución y evaluación conjunta de las iniciativas, particularmente enfocándonos en la sustentabilidad de los resultados.

-Otro bito se da en 1998, con el inicio e implementación de la Cooperación Triangular, la cual se enmarca como una estrategia intermedia entre las dos formas clásicas de Cooperación. ¿En qué consiste esta modalidad y qué beneficios concretos ha reportado al país? ¿Cómo afectan los factores culturales de cada actor en esta forma de cooperación?

-La Cooperación Triangular ha demostrado ser una herramienta eficaz. Se trata de una modalidad colaborativa que involucra a diversos actores y la AGCID asume la Cooperación Triangular como un modelo que aporta al Sistema de Cooperación Internacional para el Desarrollo. Se trata de una acción en la cual dos o más países o un organismo multilateral aúnan esfuerzos para compartir experiencias, conocimientos y recursos, de acuerdo a sus realidades y ventajas, en beneficio de un tercer país o grupo de países.

Este tipo de cooperación otorga un importante conjunto de posibilidades, tanto en el ámbito de lo financiero como en lo técnico e institucional, ya que permite impulsar proyectos de mayor complejidad y, por tanto, con un horizonte

1 Documento de la Concertación de Partidos por la Democracia de octubre de 1989, publicado originalmente con el nombre "Política, mecanismos y organización de la cooperación internacional". Citado en "Informe Final de Evaluación Proyecto de Cooperación Técnica para Países en Desarrollo ctPD, AGCI-MINREL" Gobierno de Chile, Ministerio de Hacienda, Dirección de Presupuestos. 
de acción más ambicioso.La Cooperación Triangular permite generar sinergias, pues reporta beneficios y aprendizajes para todos los socios que forman parte de un proyecto. También permite el desarrollo y transferencia de metodologías. En especial se debe destacar el marco cultural en el cual se materializa la cooperación que, al ser diverso, requiere que los distintos enfoques y miradas de los socios sean considerados, validados y respetados, lo que permite una circulación de conocimientos y saberes, disminuyendo la asimetría y fomentando la horizontalidad en el quehacer.

Un ejemplo concreto para ayudar a entender el valor de este tipo de cooperación es el programa KIZUNA, desarrollado con la cooperación japonesa, que busca mejorar las condiciones de los funcionarios públicos de la región para enfrentar situaciones de desastres. Los socios iniciales de este proyecto fueron Chile y Japón, extendiéndose hoy sus beneficios a un muy importante número de países. Para Chile, la experiencia adquirida es invaluable, pues pudo intercambiar su experiencia con uno de los países más adelantados en el mundo en materia de metodologías y procedimientos para enfrentar desastres; además de lo cual, al entregar este conocimiento, contribuye a la especialización de sus propios técnicos.

A partir de esta perspectiva, Chile reafirma y profundiza su compromiso con todos sus socios estratégicos, buscando el alineamiento de las prioridades en nuestras agendas de desarrollo respectivas en la línea de una Cooperación Triangular.

-Existen casos claros en donde se han fijado esquemas cooperativos en materias en las que no hay intereses de por medio, y que ciertamente han atendido a la consecución de Bienes Públicos Globales. No obstante ello, en su visión como diplomático, ¿̇cree usted que en otros casos la Cooperación Internacional mantiene legítimos intereses geopolíticos y/o comerciales?

-Es efectivo, la cooperación internacional resulta ser un medio apropiado para la consecución de Bienes Públicos Globales. Sin embargo, la cooperación debe ser considerada a la luz de las formas concretas de acción de los Estados y los intereses que nutren dichas acciones. La fuerza que inspira los acuerdos de cooperación, especialmente en el plano multilateral, reflejan nociones de solidaridad, de respeto y promoción de la condición humana que se mueven simétricamente con los avances civilizatorios, eso es así y debemos estar satisfechos por ello. Sin embargo, se trata de movimientos, de acciones y políticas que responden también a la voluntad de los Estados, organismos multilaterales y entidades concretas, situadas en contextos y condiciones que impiden que su forma de proceder sea necesariamente "pura". 
La pregunta apunta a mi experiencia, la personal, no a la teoría de la cooperación internacional, por eso mi respuesta tiende a inclinarse en el sentido que las entidades ya mencionadas actúan en un marco que no olvida en su proceder los intereses geopolíticos y/o comerciales que les son propios. Sin embargo, el marco civilizatorio al que hacíamos referencia, expresado en normativas, acuerdos, convenios, impide hoy que la cooperación adquiera el carácter de instrumento de intereses sectoriales. Por el contrario, pienso que día a día, adquiere una solidez mayor como mecanismo que propicia la solidaridad, la transferencia de conocimiento y el apoyo entre países, regiones y localidades.

\section{AÑOS DE GESTIÓN Y DESAFÍOS}

Para abordar los principales hitos en la historia de AGCID a lo largo de estos 30 años, su Director Ejecutivo se detiene en lo que define como momentos clave que han configurado el rol de la Agencia en la cooperación para el desarrollo nacional e internacional.

"Con la creación de la Agencia, en 1990, se inicia una etapa de institucionalización de la cooperación internacional hacia Chile y, al mismo tiempo, se lleva a cabo la tarea de canalizar hacia terceros los conocimientos adquiridos y otorgar cooperación hacia países con menor o igual desarrollo relativo. Específicamente, 1990 y 1993 fueron los años en que la Agencia fue mayormente receptora de cooperación internacional. Sin embargo, y como ya señalábamos, en junio de 1991, durante la Cumbre Presidencial Centroamericana de El Salvador, Chile manifiesta la intención de articular un programa de cooperación técnica y otorgamiento de becas para Centroamérica. Este hito marcó no solo el inicio de la Cooperación Técnica entre Países en Desarrollo (СтPD) desde Chile, sino que además le otorgó a AGCid el característico rol dual que tiene hasta hoy, que lo hace ser simultáneamente cooperante y receptor. Este mismo rol dual hace que la cooperación sea parte del desarrollo nacional y también de la política exterior", argumenta el Embajador Lira.

\section{¿¿tro momento clave fue su cambio de dependencia?}

-Por cierto, el año 2005 cambia la dependencia de AGCid desde MIDEPLAN al Ministerio de Relaciones Exteriores. Este cambio propició la coordinación, de manera más estrecha, entre la gestión de la cooperación y la política exterior de Chile. Así fue posible concretar programas de cooperación bilateral, como el caso del Fondo Chile-México, de 2006, o el Fondo Chile-España, de 2009; ambos en el marco de las nuevas estrategias generadas para coordinar esfuerzos ante un escenario internacional tendiente a disminuir los aportes de cooperación recibida. 
Siguiendo esa línea, en 2017 tuvimos que enfrentar la graduación de Chile por parte del Comité de Ayuda al Desarrollo de la ocDE, lo que significó el cese de Ayuda Oficial al Desarrollo para nuestro país en virtud del ingreso per cápita alcanzado. La importancia de este hito radica no solo en la necesidad de adaptar la cooperación chilena a este nuevo escenario, sino que, además, propició un diálogo con otros países de la región que se encontraban en una situación similar. Si bien la graduación ha significado un desafío, nos ha situado en una nueva etapa orientada en la búsqueda de nuevas estrategias de financiamiento, con el fin de encontrar un camino hacia el desarrollo a través de la reciprocidad, la solidaridad y el diálogo con distintos actores. Puedo concluir que, a lo largo de estos 30 años, la AGCID ha logrado llevar a cabo propuestas innovadoras, intentando adaptarse a los cambios y generando herramientas que le han permitido crecer en un escenario diverso, donde el desafío del desarrollo continúa y es asumido como una tarea compartida y en plena transición.

\section{-¿Cuáles son los principales desafíos en materia de Cooperación Internacional para el Desarrollo en los años venideros? ¿̇Y los desafíos de la Cooperación Chilena para el Desarrollo?}

-Sin duda que el principal desafío es seguir cooperando. Ello implica, entre otras cosas, considerar en el ámbito de la cooperación a los países emergentes, quienes demandan un tipo especial de cooperación, vale decir, toda aquella que permita sostener los procesos de desarrollo que muchos de ellos han alcanzado.

La cooperación debe, y lo está haciendo, discutir sobre la idea de desarrollo. Es fundamental comprender qué implica un proceso de esta naturaleza. La tendencia a igualar desarrollo con crecimiento es algo que de alguna manera está quedando atrás. Entendemos cada vez más que se trata de un fenómeno complejo y la cooperación internacional resulta ser un factor importante para dar cuenta de esa complejidad. Hoy, tanto en Europa como en nuestra región, estamos hablando de desarrollo en transición como un planteamiento que se incorpore en las tareas de cooperación internacional. Creemos que es un avance, puede que no todos estén de acuerdo, pero sin duda indica que el debate se está realizando. En los próximos años la cooperación internacional estará vinculada a estas reflexiones y -no puedo dejar de mencionarlo- el trabajo que estamos realizando (todos) en materia de los Objetivos de Desarrollo Sostenible (oDs) tendrá también un efecto importante. La cooperación chilena ha sido parte de los procesos que aludo, no obstante, también tiene sus peculiaridades en materia de futuro. En primer lugar, debe asumir una realidad imposible de soslayar: es un país graduado del sistema de cooperación internacional, por lo cual tiene responsabilidades ineludibles como donante. 
Luego existe un desafío en términos de liderazgo regional, la solidaridad, expresada en diversas formas de cooperación -sean estas triangular, bilateral, transversal, Fondos o diversas formas innovadoras-, que constituye una tarea muy importante en el futuro inmediato. Su destino es primordialmente Latinoamérica y se debe formular de manera simétrica, vale decir, entre iguales, sin ánimo de superioridad. Este último aspecto es relevante y la cooperación chilena debe entenderse como un camino de doble sentido: todos aquellos con quienes cooperamos tienen algo que aportarnos, no necesariamente desde la perspectiva material, pero sí desde sus experiencias, formas de resolución de conflictos, conocimientos que arrancan de sus pueblos originarios, tecnologías, arte, etc.

\section{¿¿Finalmente, cuál es el balance que realiza de su propia gestión como Director Ejecutivo de AGCID y los principales retos que enfrenta en el futuro inmediato?} -Creo que el mejor balance que puedo realizar de mi gestión se relaciona con una suerte de continuidad en la perspectiva que mantiene la cooperación chilena. Ejemplo de esto es la necesidad de enfrentar las externalidades de la condición de graduados que, a través de distintas gestiones de AGCID, han permitido transitar por este proceso sin dañar nuestras capacidades. Más bien, el tema ha permitido posicionar a Chile como un interlocutor válido en materia de desarrollo en diferentes foros internacionales. Mi labor ha sido parte de ello.

Creo que estamos enfrentando de una buena manera enormes cambios sociales, políticos, económicos e incluso culturales, en un marco de globalización cada vez más intenso. AGCID, la agencia de cooperación más antigua de la región, está trabajando por mantener una posición labrada a lo largo de 30 años, siendo un referente en la región y queremos seguir siéndolo.

Pienso que los nuevos aires en la cooperación internacional no necesariamente impiden que los países sigan recibiendo cooperación, por lo menos a nivel bilateral. En esto creo que hemos mantenido un buen paso, nuestra relación con algunos socios no se ha interrumpido y se sostiene en términos ventajosos para nuestro país, debiendo perseverar en este esfuerzo. Los desafíos en términos medioambientales son un ejemplo muy fuerte en este ámbito. De manera similar, el reto global de la actual pandemia implica un ámbito de trabajo que hace muy poco tiempo siquiera sospechábamos.

En este camino que hemos emprendido post graduación, y en el cual me ha tocado encabezar la Agencia, hemos avanzado y reaccionado mediante la construcción de nuevas estrategias. Así, resulta interesante destacar el Fondo Bilateral para el Desarrollo en Transición, firmado recientemente con la Unión Europea, el cual nos permitirá cofinanciar iniciativas que potencien distintas áreas del desarrollo nacional. Una preocupación central de esta gestión ha sido América Latina, entendida esta como nuestro domicilio. De ahí que hemos 
impulsado iniciativas enfocadas en reforzar la cooperación descentralizada, especialmente con nuestros tres países vecinos. También es muy importante consolidar la huella que la cooperación chilena va dejando en toda nuestra amplia región. Por ello hemos materializado una Red de ex Becarios, la cual permite mantener una comunicación activa con un gran número de profesionales en toda la extensión del continente. Este grupo puede ser un importante mensajero de la cooperación de Chile y de los fines que la orientan, a la par de ordenarse como motores del desarrollo en sus comunidades y países, proceso que nos interesa seguir muy de cerca.

Concluyo señalando que la cooperación contiene en su esencia el principio de la solidaridad, que tiene que ver con que nada saco con avanzar solo si dejo atrás a mis iguales, sean estos chilenos o nacionales de América Latina y el Caribe, debiendo también ocuparnos de la situación de todos los habitantes que somos mayoría al Sur del globo y que nos caracterizamos por transitar desde la pobreza y postración hacia el desarrollo y prosperidad. 
